\title{
POPULATION AND ECONOMIC GROWTH UNDER DIFFERENT GROWTH ENGINES
}

\author{
Alberto BUCCI* \\ University of Milan (Milan, Italy)
}

\author{
Xavier RAURICH \\ Universitat de Barcelona (Barcelona, Spain)
}

\begin{abstract}
Using a growth model with physical capital accumulation, human capital investment and horizontal R\&D activity, this paper proposes an alternative channel through which an increase in the population growth rate may yield a non-uniform (i.e., a positive, negative, or neutral) impact on the long-run growth rate of per-capita GDP, as available empirical evidence seems mostly to suggest. The proposed mechanism relies on the nature of the process of economic growth (whether it is fully or semi-endogenous), and the peculiar engine(s) driving economic growth (human capital investment, $R \& D$ activity, or both). The model also explains why in the long term the association between population growth and productivity growth may ultimately be negative when $R \& D$ is an engine of economic growth.
\end{abstract}

KEY-WORDS: Population growth; Endogenous and semi-endogenous economic growth; Human capital investment; Horizontal differentiation

JEL CODES: $\quad$ O41; O31; J10; J24

\footnotetext{
* Correspondence TO: Alberto Bucci, University of Milan, Department of Economics, Management and Quantitative Methods (DEMM), via Conservatorio 7, I-20122 Milan (Italy). Tel.: ++39-(0)2-50321.463; Fax: ++39(0)2-50321.505; E-mail: alberto.bucci@unimi.it. We would like to thank an Editor (prof. Mathias Hoffmann) and two anonymous reviewers of this Journal for providing constructive remarks and suggestions. An earlier version of this article was presented in the special session on Endogenous Economic Growth and Population Dynamics of the $13^{\text {th }}$ Viennese Workshop on Optimal Control and Dynamic Games (Wien, 13-16 May 2015). We thank this workshop participants, and especially Klaus Prettner, for insightful comments. This work is the result of several visits of the authors at the co-author's department. Responsibility for any remaining errors and/or omissions lies exclusively with them.
} 


\section{Introduction}

According to the United Nations' (UN, 2013, p.1) population projections, “...The world population of 7.2 billion in mid-2013 is projected to increase by almost one billion people within the next twelve years, reaching 8.1 billion in 2025 and to further increase to 9.6 billion in 2050 and 10.9 billion by 2100...”. The same report (UN, 2013, pp. 4-5) also estimates that “...Population growth until 2050 is almost inevitable even if the decline of fertility accelerates...”. These facts well explain why the evolution over time of world population and its potential effects on economic prosperity have always attracted and continue to attract the interest of economists and demographers who, since Malthus (1798), have attempted to find a possibly unambiguous answer to the following question: What is the sign of the relationship between population growth and economic growth in the long-run?

On the theoretical side, three schools of thought in the past two centuries have provided three entirely different answers to this question. As for the pessimists (Malthus, 1798; Coale and Hoover, 1958; Ehrlich, 1968), with fixed resources - especially land, physical capital and knowledge capital- population growth hampers economic growth. The optimists (Kuznets, 1967; Boserup, 1981; Simon, 1981; Romer, 1986 and 1990; Kremer, 1993; Jones, 1995), instead, believe that once technological progress is allowed to be endogenously determined within the model, the impact of population growth on economic growth is definitely positive because larger populations stimulate the advancement of technical change, are able to enjoy greater economies of scale, and are likely to have a greater number of geniuses. Finally, a third school of thought ("Population Neutralism") recognizes that population growth has no effect on a country's economic growth prospects. Within the neo-classical growth theory, Solow (1956) was the first to show that in a steady state the growth rate of real per-capita income is eventually determined just by the rate of technical change, an exogenous variable.

Similarly, available evidence also appears by no means conclusive about the net impact of population growth on economic growth (i.e., growth of per-capita income). For instance, after using a world sample of 78 countries covering the period from 1965 to 1990, Williamson (2003, pp. 113-115) shows that there is no significant relationship between the two variables. This outcome is consistent with the "neutralist" position. However, he also shows that the result is sensitive to the empirical specification employed as, when the log of life-expectancy in 1960 and two further variables controlling for economic geography are added, population growth is shown to generate a positive and significant impact on GDP per capita growth, which supports the "optimist" position. On the other hand, different recent empirical works (for example, Li and Zhang, 2007; Herzer et al., 2012) find a definitely negative effect of population growth on economic growth.

Summing up, it seems that the main conclusion of the path-breaking paper by Kelley and Schmidt (1995, p. 554) still continues to hold today: “...This analysis...provides a more balanced perspective on 
the consequences of demographic change because it rests on the proposition that population growth has both negative and positive effects...As this paper demonstrates, population growth is not all good or all bad for economic growth: it contains both elements, which can and...do change over time”.

Inspired by such a conclusion, many economists now believe that the relationship between population growth and economic growth is non-linear, and possibly non-monotonic. For example, an inverted-U shaped relation between population growth and per-capita GDP growth is found in the data by Saccone and Valli (2011, p. 8, Fig. 2), who use a cross-country sample of 93 countries over the period 1980-2010.

Our model aims at characterizing another (complementary) mechanism by which an increase in the whole population growth rate (an exogenous variable) may yield a non-uniform (i.e., a positive, negative, or else neutral) impact on the growth rate of per-capita GDP across countries and/or over time, as available empirical evidence mostly suggests. So, while it is not our objective to explain fertility and to capture the mutual evolution of population, technology, human capital and per capita income along most of human history, ${ }^{1}$ the salient feature of our analysis that makes it novel with respect to other comparable works in the literature (including the path-breaking contribution by Strulik, 2005²) is that it considers a framework where simultaneously individuals invest in physical and human capital, and firms perform R\&D activity. In particular, unlike the canonical Romer (1990)'s and Jones (1995)'s settings, we consider the possibility that the intermediate sector uses also human capital (a reproducible factor), along with physical capital, as an input. Hence, in our model human capital is employed to produce new human capital, final and intermediate goods/inputs, and to invent new ideas. Depending on the aggregate returns to scale in the key (R\&D and human capital) production functions, our modelling strategy allows us to describe an economy in which long-run economic growth may be either fully- or semi- endogenous and driven either solely by human capital investment, or solely by $\mathrm{R} \& \mathrm{D}$, or by both activities. Within this environment, we are able to explain the differential impact that in the long-run a given change in the population growth rate may have on economic growth through: (i) The nature (fully- or semiendogenous) of the process of economic growth, and (ii) The peculiar engine(s) driving economic growth.

Other works that we consider somehow close to ours include Boucekkine et al. (2002), Mierau and Turnovsky (2014), and Bucci (2008; 2013). In Boucekkine et al. (2002) there is no R\&D activity, and the relation between population and economic growth rates is hump-shaped regardless of the sources of demographic change. This result is obtained thanks to the vintage nature of the accumulated human capital. Despite the fact that in Mierau and Turnovsky (2014), who use a single-sector endogenous growth framework à la Romer (1986), the link between the whole population growth rate and the economic

\footnotetext{
1 Papers that already do this include, among many others, Galor and Weil (1999; 2000), Galor and Moav (2002), Jones (2001), Kogel and Prskawetz (2001).

2 Strulik (2005) introduces human capital accumulation in an R\&D-based growth model with expansion in variety and quality of goods. In his setting, however, there is no physical capital accumulation.
} 
growth rate is monotonic, their model is still able to account for a hump-shaped relation between the two variables since population growth can be explained by either an increase in fertility or a reduction in mortality. Thus, as in Kelley and Schmidt (1995), in Mierau and Turnovsky (2014) the way in which population growth occurs is important in rendering the relationship between demographic change and economic growth ultimately non-uniform in sign. Using an endogenous growth model with (non-vintage) human capital investment and purely horizontal R\&D activity, Bucci (2008) postulates that the investment in skill-acquisition by agents may be either positively, or negatively, or else not influenced at all by technological progress. In the first case, a faster technical progress by increasing the demand for skills induces agents to accumulate more human capital (skill-biased technical change hypothesis). In the second case, technical progress exerts a sort of "erosion" on human capital acquisition as being able to use new technologies takes time ("eroding" technical change hypothesis). Finally, in the last case individual incentives to invest in schooling are totally independent of the nature/direction of technical change (neutral technical change hypothesis). The main result of the paper (Bucci, 2008, Table 1, p. 1141) is that, along a balanced growth path equilibrium and for non-extreme values (namely, for values different from zero and one) of the parameter that measures the degree of altruism towards future generations, only the presence of skill-biased technical change is compatible with the existence of a non-uniform relationship between population growth and per capita income growth. So, the novelty of Bucci (2008) consists in tying the possibly undetermined sign of the correlation between population growth and economic growth in the long-run to the nature/direction of technical change. Intuitively, an increase of population leads to a fall of per-capita income (due to the traditional dilution effect) and to a major number of innovations. If technical change is skill-biased (meaning that it spurs the demand and, thus, the consequent supply of human capital, the model's growth engine), then per-capita income rises. Accordingly, the final effect on economic growth exerted by population growth may well be positive, negative, or exactly equal to zero. In Bucci (2013), instead, the focus is not on the nature/direction of technical change, but rather on the fact that an expansion in intermediate-inputs variety may generate not only benefits (in terms of greater specialization) but also costs (in terms of more complexity in assembling the different available varieties of intermediates in the aggregate production function). In this framework, again, a rise of population has two opposing consequences on long-term per-capita income growth: the first is negative (and operates through the dilution-effect of population), whereas the second (under the common hypothesis of Benthamite-type preferences) is always positive (more people lead to more ideas, this is the ideas-effect). In this context, the lower the 'complexity' of combining a larger number of differentiated intermediates in the process of producing final goods, the higher the returns to specialization, and hence the larger the positive ideas-effect in comparison with the negative dilutioneffect of population (so that, as population increases, we may observe that the effect of population growth 
on economic growth turns from negative into positive). Differently from the last two papers, in the present article we model neither the possible effect of technical change on human capital accumulation nor the possible trade-off between potential benefits and potential costs related to intermediate-inputs proliferation in the aggregate production function. Instead, as mentioned above, we are interested here in emphasizing a totally new mechanism through which the relation between population and economic growth rates might be non-uniform in sign in the long-term.

Another related objective of the current analysis is to provide a different explanation as to why in R\&Dbased growth models the long-run (as opposed to the off-steady-state) association between population growth and productivity growth could be negative. In this regard, we claim that when R\&D (alone, or together with human capital investment) is an engine of fully-endogenous economic growth, an increase in the population growth rate raises the growth rate of aggregate human capital and the share of skilled labor devoted to accumulate skills. As a consequence, population growth reduces the share of skilled labor employed in the R\&D sector, which ultimately leads to a smaller growth rate of per capita GDP. Thus, the model explains the possibly negative long-run correlation between population and economic growth rates in R\&D-based models through a reallocation of skilled labor away from $R \& D$ activity. This mechanism is different from the one recently suggested by Strulik et al. (2013) who, in order to explain why earlier R\&D-based growth models are unable to predict a negative relationship between population growth and economic growth, introduce a child quantity-quality trade off in an otherwise standard Romer (1990)Jones (1995) model. The presence of such a trade-off is at the core of what they call "populationproductivity reversal" in R\&D-based growth. This term was introduced by Strulik et al. (2013) to specifically describe the off-steady state phenomenon that along the transition to modern growth population growth is first positively and then negatively correlated with productivity growth. According to them, during the fertility transition the increase of individual human capital endowment overcompensates the associated decline of population in a way that leads to a rise of the aggregate human capital stock. Given that human capital is the driving force in $R \& D$ activity, this causes at some point in time higher R\&D output and, hence, higher R\&D-based growth. The conclusion is, thus, that when the child quantityquality trade-off is operative, productivity growth can be negatively correlated with population growth even in typical R\&D-based growth models. In a companion paper, Prettner (2014) proposes another way through which higher population growth can negatively affect economic growth within a Romer (1990)Jones (1995)'s economy: an increase in population growth, while positively influencing aggregate human capital accumulation, decreases simultaneously schooling intensity (defined as the productivity of teachers times the public resources spent on educating each child). The fall of schooling intensity has, in turn, a negative impact on the future evolution of aggregate human capital. If the negative effect dominates, the 
resulting slowdown of aggregate human capital accumulation eventually reduces technological progress and, therefore, economic growth.

Our model also reaches other conclusions. The first is that when growth is semi- or fully-endogenous, but driven solely by human capital accumulation, then population growth continues to have an unambiguously positive effect on economic growth, provided that the R\&D sector is operative. Intuitively, since in these cases the productivity of R\&D activity increases with the aggregate stock of human capital, which in turn rises with population growth, following an expansion of population the R\&D sector produces more designs per unit of time, which enhances the long-run growth rate of per capita income. Moreover, we find that when fully-endogenous economic growth is jointly driven by human capital investment and R\&D activity, then increasing the efficiency of the education sector may also yield a negative impact on economic growth. This outcome depends on the fact that a rise in the total factor productivity (TFP) of this sector brings about an increase in the growth rate of aggregate human capital and a reduction in the share of the skilled labor employed in $R \& D$, which causes a fall in the growth rate of the number of ideas. If the second effect dominates, then the growth of per capita GDP decreases with the education sector's efficiency (TFP).

The paper is structured as follows. The next section sets up the model. Section 3 analyzes the possible long-run equilibria that our model may yield and focuses on symmetric balanced growth path (BGP) equilibria. Section 4 studies the relationship between population growth and per capita GDP growth in four possible symmetric BGP equilibria. They differ by the type (fully endogenous vs. semi-endogenous) and the source (human capital investment, R\&D activity, or both) of long-run economic growth. Section 5 discusses the main results and concludes.

\section{The model}

Consider a closed economy where three sectors of activity are vertically integrated. The research sector is characterized by perfect competition and free entry. Here, firms combine human capital and the existing number of ideas to engage in innovative activity that results in the invention of new blueprints for firms operating in the intermediate sector. This sector is, in turn, composed of monopolistically competitive firms. There is a distinct firm producing a single variety of intermediate inputs and holding a perpetual monopoly power over its sale. The intermediate inputs are combined with human capital to produce a homogeneous final good. A more thorough description of the production side of the economy follows. 


\subsection{Production}

The final-output sector is populated by a very large number of atomistic firms, each producing the same good. A representative firm employs a constant returns to scale aggregate production function taking the form:

$$
Y_{t}=A H_{Y, t}^{1-\alpha} X_{t}^{\alpha}, \quad A>0, \quad 0<\alpha<1 .
$$

In (1), $Y$ is total output of the final good (the numeraire in the model), $H_{Y}$ is the amount of human capital employed in the whole industry, $A$ measures the sectorial TFP, and $(1-\alpha)$ is the elasticity of GDP with respect to human capital. $X_{t}$ is a composite of intermediate inputs, $x_{i}$, that satisfies:

$$
X_{t}=\left[\int_{0}^{N_{t}}\left(x_{i, t}\right)^{1 / m} d i\right]^{m},
$$

where $N$ is the number of varieties of intermediates already existing and $m \geq 1$ is a technological parameter which determines the elasticity of substitution between two generic varieties of such intermediates, $m /(m-1)$. A decrease in $m$, by raising the substitutability between any generic pair of intermediate inputs, leads to tougher competition across capital-goods producers and, ceteris paribus, to lower prices. Thus, $m$ can be used as a measure of the degree of competition in the intermediate product market. When $m=1$, there is perfect competition in the intermediate sector (any two varieties of intermediates are perfect substitutes with each other). Profit maximization and perfect competition in the final output sector imply that the inverse demand function for the $i$-th intermediate is:

$$
P_{i, t}=\alpha Y_{t}\left(\frac{x_{i, t}^{1-m}}{X_{t}}\right)^{\frac{1}{m}},
$$

where $P_{i, t}$ is the price of the $i$-th intermediate good. In the absence of any strategic interaction across firms operating in the intermediate sector, the demand for the $i$-th intermediate input has price elasticity (in absolute value) equal to $m /(m-1)>1$, which coincides with the elasticity of substitution between any two generic varieties of intermediates in the production of final output. Profit maximization also implies that the wage in the final output sector is equal to

$$
w_{t}^{Y}=(1-\alpha) \frac{Y_{t}}{H_{Y, t}} .
$$

As the economy is closed and there is no governmental activity, the output of this sector can be devoted to either consumption or investment. Thus, the aggregate resource-constraint reads as

$$
\dot{K}_{t}=Y_{t}-C_{t}, \quad K_{0}>0 .
$$

Following Romer (1990, Eq. 2, p. S82), in Eq. (4) we explicitly abstract from any depreciation of the physical capital stock ( $K$ ). 
In the intermediate sector, firms engage in monopolistic competition. Each of them produces a different variety of intermediate inputs. We assume that intermediate firms have access to the same technology:

$$
x_{i, t}=B k_{i, t}^{\beta} h_{i, t}^{1-\beta}, \quad \forall i \in\left[0, N_{t}\right], \quad N_{t} \in[0 ; \infty),
$$

where $h_{i}$ (respectively, $k_{i}$ ) is the amount of human (physical) capital required in the production of the $i$-th intermediate input whose output is $x_{i}, B>0$ measures the TFP of the sector, and $\beta \in(0,1]$ is the physical capital output elasticity. Eq. (5) represents an important departure from Romer (1990), as it states that both physical capital and labor (human capital) are inputs in the production of intermediate inputs when $\beta \in(0 ; 1)$. With $\beta=1$, instead, we are back to the canonical Romer (1990, p. S82)'s specification.

The instantaneous profit of the generic intermediate firm $i$ is:

$$
\pi_{i, t}=P_{i, t} x_{i, t}-w_{i, t}^{I} h_{i, t}-r_{i, t} k_{i, t},
$$

where $w_{i, t}^{I}$ is the wage paid by the firm producing the $i$-th intermediate input and $r_{i, t}$ is the interest rate faced by the same firm. Continuing to assume that there is no strategic interaction across firms in the intermediate sector, so that each of them takes $X_{t}$ as given, maximization of (6) with respect to $h_{i}$ and $k_{i}$ and subject to (1), (2) and (5) delivers:

$$
w_{i, t}^{I}=\frac{\alpha(1-\beta) Y_{t}}{m h_{i, t}}\left(\frac{X_{t}}{X_{t}}\right)^{1 / m},
$$

and

$$
r_{i, t}=\frac{\alpha \beta Y_{t}}{m k_{i, t}}\left(\frac{x_{t}}{X_{t}}\right)^{1 / m} .
$$

We follow the literature in focusing on a symmetric equilibrium where not only $x_{i, t}=x_{t}$, but also

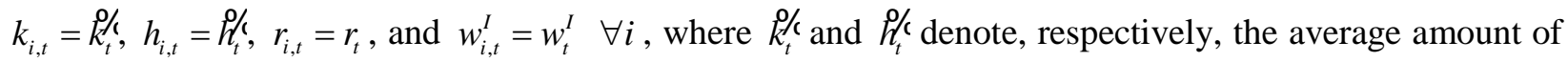
physical and human capital inputs employed by the existing intermediate firms. Thus, in a symmetric equilibrium, the last two equations can be re-cast as:

$$
w_{i, t}^{I}=\frac{\alpha Y_{t}}{m} \frac{(1-\beta)}{N_{t} h_{t}^{0}}=w_{t}^{I}, \quad \forall i \in\left[0, N_{t}\right]
$$

and

$$
r_{i, t}=\frac{\alpha Y_{t}}{m} \frac{\beta}{N_{t} k_{t}^{0 / 0}}=r_{t} \quad \forall i \in\left[0, N_{t}\right]
$$

The aggregate stocks of physical and human capital employed in the intermediate inputs sector are, respectively, $K_{t} \equiv N_{t} k_{t}^{0 /(}$ and $H_{I, t} \equiv N_{t} h_{t}^{\circ}$. In a symmetric equilibrium, (7) and (8) imply

$$
H_{I, t}=\frac{\alpha Y_{t}}{m} \frac{(1-\beta)}{w_{t}^{I}},
$$

and 


$$
K_{t}=\frac{\alpha Y_{t}}{m} \frac{\beta}{r_{t}}
$$

and the production function in the intermediate sector simplifies to

$$
x_{i, t}=B \frac{K_{t}^{\beta} H_{I, t}^{1-\beta}}{N_{t}}=x_{t}, \quad \forall i \in\left[0, N_{t}\right] .
$$

Finally, using (7), (8), the definition of $X_{t}$, and the hypothesis of symmetry, the instantaneous flow of profits of the generic $i$-th intermediate firm (6) can be written as:

$$
\pi_{i, t}=\alpha\left(\frac{m-1}{m}\right) \frac{Y_{t}}{N_{t}}=\pi_{t}, \quad \forall i \in\left[0, N_{t}\right] .
$$

According to (12), the instantaneous profit of a generic firm $i$ would, ceteris paribus, be equal to zero under perfect competition $(m=1)$.

\subsection{Research and development (R\&D) activity and human capital investment}

There are many small competitive firms undertaking R\&D activity. These firms produce ideas that take the form of new varieties of intermediate inputs used in the production of final output. They are partially excludable, but non-rival. With access to the same stock of knowledge, $N$, a representative research-firm uses only human capital to develop new ideas according to the following production function

$$
\dot{N}_{t}=\Gamma_{t} H_{N, t}, \quad N_{0}>0,
$$

where $H_{N}$ is the research human capital input and $\Gamma_{t}$ is the rate at which any single researcher can generate a new idea. We posit that $\Gamma_{t}$ has the following specification:

$$
\Gamma_{t} \equiv \frac{1}{\chi} \frac{N_{t}^{\varepsilon}}{H_{t}^{\phi}} .
$$

Since the representative R\&D-firm is small enough with respect to the whole sector, it regards $\Gamma_{t}$ as given. In (14), $H_{t}$ is the aggregate stock of human capital available in the economy and $\chi>0, \phi \leq 1$ and $\varepsilon \leq 1$ are technological parameters. The inverse of $\chi$ is the R\&D-sector TFP and the other two parameters measure the intensity of two distinct effects. $\varepsilon$ measures the way in which the current stock of knowledge, $N_{t}$, affects the invention of new ideas. When $\varepsilon<0$ the rate at which a new innovation arrives declines with the existing stock of knowledge ("fishing out effect"). If $0<\varepsilon \leq 1$, an increase in $N_{t}$, instead, raises the rate at which a new innovation appears ("standing on shoulders effect"): this can occur either proportionally $(\varepsilon=1)$ or less than proportionally $(0<\varepsilon<1) .{ }^{3}$ Finally, $\varepsilon=0$ represents the case in which the arrival rate of a new idea is independent of the existing stock of knowledge. Similarly, $\phi$

\footnotetext{
3 For an in-depth discussion of the "fishing out" and "standing on shoulders" effects, see Jones (1995; 2005).
} 
measures the strength of the externality arising from the aggregate stock of human capital available in the economy, $H_{t}$. In order to explain in detail the main implications of such externality, assume $0<\phi<1$, and imagine that a given share $s_{N, t}$ of $H_{t}$ is employed at each time $t$ as research-human capital $\left(H_{N, t}\right)$. Hence, by combining (13) and (14), and using $H_{N, t}=s_{N, t} H_{t}$, we have:

$$
\dot{N}_{t}=\frac{1}{\chi} \frac{N_{t}^{\varepsilon}}{H_{t}^{\phi}} H_{N, t}=\frac{1}{\chi} \frac{N_{t}^{\varepsilon}}{H_{t}^{\phi}} S_{N, t} H_{t}=\frac{1}{\chi} N_{t}^{\varepsilon} S_{N, t} H_{t}^{1-\phi} .
$$

This equation suggests that, ceteris paribus (that is, for given $N_{t}$ and $s_{N, t}$, and for given parameters $\chi>0$ and $\varepsilon \leq 1)$, the term $H_{t}^{-\phi}$ introduces decreasing returns to $H_{t}$ in the production of new ideas $\left(\dot{N}_{t}\right)$. Thus, when $0<\phi<1$, having a larger amount of $H_{t}$ leads simultaneously to a proportional increase in $H_{N, t}$ and to a less than proportional increase in the production of new ideas per unit of time, $\dot{N}_{t} \equiv d N_{t} / d t$. In the limit (i.e., $\phi=1$ ), changes in $H_{t}$ would yield no direct effect on $\dot{N}_{t} \equiv d N_{t} / d t$. In a word, when $0<\phi \leq 1$ a rise of $H_{t}$ causes the researchers' productivity to decline. We postulate that this occurs because the ultimate effect of having more human capital in the economy and, therefore, more researchers and more research projects for horizontal innovations, is to "congest" the whole R\&D sector, which reduces the speed at which future new ideas for new varieties of intermediates can be developed. This view complements the belief (see Ha and Howitt, 2007, Eq. 5, p. 740) that having more human capital $H_{t}$, by resulting in more horizontal innovations, may lead to a dilution of any given research effort over a larger amount of separate $R \& D$ projects. Still, we think that our mechanism, based on the presence of negative congestion-externality effects (associated to aggregate human capital, $H_{t}$ ) in research when $0<\phi \leq 1$, is different from the Jones' (1995) mechanism based, instead, on the existence of negative duplication-externality effects (related to the total number of people allocated to the R\&D sector, $H_{N, t}$ ). Even the more recent Jones' (2005) formulation of the invention process does not take into account the possible existence in R\&D activity of congestion-externality effects due to an economy's total stock of human capital. ${ }^{4}$

A representative $R \& D$ firm has instantaneous profits equal to

$$
\pi_{N, t}=\Gamma_{t} H_{N, t} V_{N, t}-w_{t}^{N} H_{N, t},
$$

4 Although we consider the case where $\phi$ is positive as the most relevant, our analysis holds also when $\phi \leq 0$. In particular, when $\phi=0$ Eqs. (13) and (14) together deliver: $\dot{N}_{t}=\frac{1}{\chi} H_{N t}^{\psi} N_{t}^{\varepsilon}$, with $\psi=1>0$, and $\varepsilon \leq 1$. This specification is consistent with Jones (2005, Eq. 16, p. 1074), where $\varepsilon$ is postulated to be strictly smaller than one. 
where $w_{t}^{N}$ is the wage paid to one unit of human capital employed in the research sector and $V_{N, t}$ is the price of the $i$-th idea. This price is, in turn, equal to the discounted value of expected profits obtained from the discovery and subsequent production of the $i$-th variety of capital-goods,

$$
V_{N, t}=\int_{t}^{\infty} \pi_{i, \tau} e^{-\int_{t}^{\tau} r(s) d s} d \tau, \quad \tau>t .
$$

Perfect competition in the R\&D sector delivers the following zero-profit condition:

$$
w_{t}^{N}=\Gamma_{t} V_{N, t} .
$$

In this economy there is just one (representative) household. The number of members of this household is $L$. Hence, $L$ is also the size of the whole population in the economy. Each individual may purposefully invest in education. We assume that aggregate human capital $(H)$ evolves according to:

$$
I_{t}=\sigma\left(1-u_{t}\right) H_{t} \bar{h}_{t}^{\mu-1}, \quad H(0)>0
$$

where $\sigma>0$ is the TFP of the education sector, $(1-u) \in[0 ; 1]$ is the fraction of the existing human capital employed in educational assignments, $\bar{h} \equiv H / L$ denotes the average level of skills available in the whole population, and $0<\mu \leq 1$ is a parameter. According to this formulation, when $0<\mu<1$ a negative externality arising from the average level of human capital already attained operates in the process of new human capital formation $(\dot{H})$. Before motivating the presence of such externality, it is worth writing the law of motion of human capital per capita $(h)$ as:

$$
\dot{h}_{t}=\sigma\left[\left(1-u_{t}\right) h_{t}\right] \bar{h}_{t}^{\mu-1}-n h_{t}, \quad h(0)>0,
$$

where $n \equiv \dot{L}_{t} / L_{t}$ is the economy's exogenous population growth rate. This equation makes apparent that, because newborns are totally uneducated and enter the workforce/population with zero human capital, they negatively affect the accumulation of human capital per capita through a dilution-effect (the term -nh in Eq. 18). In other words, population growth works like a form of depreciation of human capital per capita (Strulik, 2005, p. 135).

Along a symmetric equilibrium in which human capital per capita coincides with the average level of human capital available in the population, i.e. $h=\bar{h} \equiv H / L$, Eq. (18) trivially simplifies to

$$
\dot{h}_{t}=\sigma\left(1-u_{t}\right) h_{t}^{\mu}-n h_{t}, \quad h(0)>0 .
$$

In Eq. (19), $0<\mu \leq 1$ clearly measures the returns to human capital per capita in the production of new per-capita human capital: in the model, such returns may be either constant $(\mu=1)$ or decreasing $(0<\mu<1)$. 
In order to explain economically Eqs. (18) and (19), neglect for a moment the presence of the population dilution-effect, whose plausibility is now extensively supported, both empirically and theoretically. ${ }^{5}$ It is well known that in Lucas (1988) the production of per capita human capital involves the combination of two inputs, namely the level of human capital already attained and the amount of time allocated to its accumulation. Lucas (1988, Eq. 13) assumes that these two inputs are combined according to $\dot{h}(t)=h(t) \delta[1-u(t)]$, which is linear in $h$. This linearity assumption has been strongly criticized on empirical grounds. ${ }^{6}$ In particular, Trostel (2004) has demonstrated that in the data the relation between $\dot{h}$ and $h$ is definitely non-linear, as human capital production displays significant decreasing returns at high levels of educational attainment (cumulative years of schooling). ${ }^{7}$ The presence of decreasing returns to education in generating additional human capital is evident from Eq. (19) when $0<\mu<1$. We explicitly claim (Eq. 18) that such decreasing returns originate from a negative externality associated to the average human capital level already existing in the economy: the higher the level of human capital that, on average, has already been attained the more difficult it is to produce new human capital per capita (Gong et al., 2004, p. 403). Furthermore, there is another compelling argument against the traditional Lucas' (1988) formulation of the process of acquiring human capital per capita through education. Indeed, an

5 Boikos et al. (2013, p. 56) conclude their empirical analysis on the relation between $h / h$ and $n$ by stating: “...At first there seems to be a negative relationship between the birth rate and human capital by using a linear specification corresponding to the benchmark model...Re-estimation of the human capital-birth rate nexus using semi-parametric and non-parametric methods reveals the presence of a strong non-monotonic relationship. However, even in the presence of non-monotonicity the dilution effect dominates any positive effect that comes from the accumulation effect for most of the observations in our sample...”. In their analysis, the accumulation effect is measured by $\partial[\sigma(1-u)] / \partial n$. Recall that in the absence of immigration and mortality, there is a one-to-one correspondence between the population growth rate and the birth (or fertility) rate. The presence of an inverse relationship between education and the birth rate is, indeed, a typical outcome of any unified growth model based on the child quantity-quality trade-off. According to Galor (2005, p. 239), the existence of a trade-off between quantity and quality of children is indeed a very-well empirically supported fact.

6 See 'the linearity critique' of Jones (2005, p. 1104).

7 By building a simple theoretical model, Trostel (2004) shows that the returns to scale (from education) in human capital production can be inferred directly from the marginal rate of return to education (a similar result was also established by Bils and Klenow, 2000). In other words, an observed constant (declining, rising) marginal rate of return to education is indicative of constant (decreasing, increasing) returns to scale in producing human capital through education. In traditional Mincerian wage regressions (see Psacharopoulos and Patrinos, 2004 for an international comparison) typically there appears only a linear schooling term, hence in general those regressions can solely conclude that returns to education are high when education is low and low when education is high, resulting in Mincer returns that are significantly decreasing with educational attainment. In the nonlinear extension of the standard Mincer (1974) wage equation, Trostel (2004, p. 465) demonstrates that in the data the presence of a cubic term in the variable 'schooling' (cumulative years of schooling) represents a better representation of the relation between schooling attainment and wages. His results reveal that in market economies (Table 3, p. 470), for example, the estimated marginal rate of return to education is maximized at a value of $7.8 \%$ when the cumulative years of schooling $(S$ ) equal 12.14. When $S>12.14$, such rate declines implying that after that threshold we observe decreasing returns to scale in producing human capital through education. 
additional theoretical implication of that formulation is that an increase in the time devoted to human capital formation raises monotonically the growth rate of human capital (scale effect). According to the same authors mentioned above (Gong et al., 2004), however, this implication of the model is easily falsified in the data since for a country like the United States, for example, in recent decades the time series of the growth rate of human capital and the time series of time spent for education clearly show that it is not true that the first variable (the growth rate of human capital) increases one-to-one with the second (time spent for education). In other words, Gong et al. (2004) maintain that the original version of the Lucas (1988) model is not consistent with recent aggregate time-series evidence. Accordingly, in our model we break down the overly restrictive relation between time spent for education and per capita human capital growth that it is possible to observe in Lucas (1988). All in all, in Eqs. (18) and (19) we modify the basic Lucas' human capital accumulation equation so as to make that model more compatible with the available empirical evidence about the relation between educational levels already acquired and the generation of new human capital, and to explicitly account for a dilution-effect of population growth in the process of per-capita skill acquisition.

Perfect mobility of human capital across sectors implies wage equalization, and thus

$$
w_{t}^{Y}=w_{t}^{I}=w_{t}^{N} \equiv w_{t} .
$$

Human capital is fully employed in the three sectors. This implies:

$$
u_{t} H_{t}=H_{Y, t}+H_{I, t}+H_{N, t} .
$$

Eq. (21) says that the fraction of the available aggregate human capital stock employed in production and R\&D activities should be equal at equilibrium to the sum of the sectorial demand for human capital. After defining by $s_{Y, t} \equiv H_{Y, t} / H_{t}, s_{I, t} \equiv H_{I, t} / H_{t}$ and $s_{N, t} \equiv H_{N, t} / H_{t}$ the shares of the available aggregate stock of human capital ( $H$ ) devoted respectively to the production of final output and intermediate inputs and to the discovery of new ideas, (21) can be re-written as:

$$
u_{t}=s_{Y, t}+s_{I, t}+s_{N, t} \text {. }
$$

As a final comment, one may easily observe that human capital is in our framework an important input not only in the production of final goods and intermediate inputs but also in R\&D and educational (teaching) activities, and that no other inputs (such as, for example, physical capital and/or final output) are required in the latter two sectors. Moreover, we do not include the stock of knowledge $(N)$ as a possible determinant of the productivity of the teaching sector. While formal inclusion and consideration of all these new ingredients would make our model closer to reality, we prefer to focus here on the most parsimonious and tractable possible model able, at the same time, to generate all the effects/explanations that the present analysis aims at putting forward (with particular attention to a re-allocation effect, to be introduced shortly). 


\subsection{Consumers}

The representative, infinitely-lived household maximizes the discounted value of the sum of utilities from consumption, $u\left(c_{t}\right)=\frac{c_{t}^{1-\theta}-1}{1-\theta}$, of its members:

$$
U=\int_{0}^{\infty} u\left(c_{t}\right) L_{t} e^{-\rho t} d t=\int_{0}^{\infty}\left(\frac{c_{t}^{1-\theta}-1}{1-\theta}\right) e^{-(\rho-n) t} d t,
$$

where $c \equiv C$ / $L$ denotes consumption per household-member (consumption per capita), $L$ is the number of household-members (the economy's population size), and $\theta>0$ is the inverse of the intertemporal elasticity of substitution in consumption. For constant population growth $(n)$, the initial population size has been normalized to one in the last part of (23). In the same equation, $\rho$ denotes the subjective discount rate. The assumption $\rho>n \geq 0$ is important as it implies that $U$ is bounded if $c$ remains constant over time. Let $k \equiv K / L$ denote physical capital per capita. The budget constraint in per capita terms is:

$$
\dot{k}_{t}=\left(r_{t}-n\right) k_{t}+w_{t} u_{t} h_{t}-c_{t}, \quad k(0)>0,
$$

where wuh is the per capita human-capital-income and $r k$ is the per capita capital-income. The household chooses the optimal paths of per-capita consumption (c) and of the share of human capital to be devoted to production activities ( $u$ ) by maximizing (23) subject to (24) and (18). Online-Appendix A shows that the solution to this maximization problem in a decentralized, ${ }^{8}$ symmetric equilibrium is represented by the Euler equation

$$
\gamma_{c} \equiv \frac{\dot{C_{t}}}{c_{t}}=\frac{1}{\theta}\left(r_{t}-\rho\right)
$$

and by the following non-arbitrage condition between physical and human capital, which determines the growth rate of wages 9

$$
\gamma_{w} \equiv \frac{\dot{w_{t}}}{w_{t}}=r_{t}-\sigma h_{t}^{\mu-1}+(\mu-1) \frac{\dot{h}_{t}}{h_{t}}
$$

8 In a decentralized equilibrium each individual, because too "small" with respect to the entire population/household, takes the average level of human capital already attained, $\bar{h}$, as given (thus ignoring that, when $\mu<1$, increasing her/his level of human capital simultaneously makes it more difficult for other agents to raise their own level of human capital).

9 As it can be seen in Online-Appendix A, the relative price between physical and human capital is $q=\frac{w}{\sigma h^{\mu-1}}$. It follows that (26) can be rewritten as $\dot{q}+w=q r$, which equates the return of one unit of human capital to the return of one unit of physical capital. 


\section{The symmetric BGP equilibrium}

We can now introduce the following two definitions.

Definition 1. A symmetric equilibrium in this economy is a path $\left\{c_{t}, k_{t}, h_{t}, u_{t}, s_{Y, t}, s_{I, t}, s_{N, t}, w_{t}, r_{t}\right\}_{t=0}^{t=+\infty}$ along which:

(i) Every individual in the population has the same level of human capital, i.e. $h_{t} \equiv H_{t} / L_{t}=\bar{h}_{t}$;

(ii) Every intermediate firm $i$ employs the same amount of physical and human capital inputs, i.e. $k_{i t}=k_{t}^{0 /}$ and $h_{i t}=h_{t}^{0}$, so that $x_{i t}=x_{t} \forall i$;

(iii) Eqs. (1), (3), (7), (8), (13), (14), (16), (18), (20), (22), (24), (25), and (26) are satisfied.

Definition 2. A symmetric BGP equilibrium in this economy is a symmetric equilibrium path along which:

(i) The allocations of human capital, both between activities -education and production, $u \in(0 ; 1)-$ and across sectors -production of final goods $\left(0<s_{Y}<1\right)$, production of intermediate inputs $\left(0<s_{I}<1\right)$, and invention of new ideas $\left(0<s_{N}<1\right)$ - are all constant;

(ii) The growth rate of each variable is constant, and possibly positive.

We are now able to characterize the model's symmetric BGP equilibrium. To this end, in what follows we denote by $\gamma_{Z}$ the growth rate of any generic variable $Z$. Eq. (25) and the constancy of the growth rate of per capita consumption imply that the real rate of interest $(r)$ is also constant. Eq. (8) and the interest rate being constant imply:

$$
\gamma_{K}=\gamma_{Y}
$$

In a symmetric BGP equilibrium, the sectorial allocation of human capital is also constant, i.e. $S_{Y}, s_{I}$ and $s_{N}$ are constant. Together with (3) and (20), this implies:

$$
\gamma_{w}=\gamma_{Y}-\gamma_{H} \text {. }
$$

From (13) and (14), we obtain the growth rate of ideas $(N)$ as:

$$
\gamma_{N}=\left(\frac{s_{N}}{\chi}\right) H_{t}^{1-\phi} N_{t}^{\varepsilon-1} .
$$

Because $\gamma_{N}$ and $s_{N}$ are positive constants along a symmetric BGP, from (29) it follows that:

$$
\gamma_{N}=\left\{\begin{array}{lllll}
\left(\frac{1-\phi}{1-\varepsilon}\right) \gamma_{H} & \text { if } & \phi \leq 1 & \text { and } & \varepsilon<1 \\
\left(\frac{s_{N}}{\chi}\right) H_{t}^{1-\phi} & \text { if } & \phi \leq 1 & \text { and } & \varepsilon=1
\end{array}\right.
$$

Moreover, from the resource-constraint (4) and (27) we obtain: 
In a symmetric BGP equilibrium, (7) implies:

$$
\gamma_{C}=\gamma_{K}
$$

$$
w_{t}^{I}=\frac{\alpha(1-\beta)}{m s_{I}}\left(\frac{Y_{t}}{H_{t}}\right) .
$$

According to (16), $w_{t}^{N}$ depends on the price of new designs. The following assumption guarantees that the long-run values of both the price of a new design and $w_{t}^{N}$ are finite:

\section{Assumption A: $\quad r>\gamma_{Y}-\gamma_{N}$.}

Under this assumption, from (12) and (15), we obtain:

$$
V_{N, t}=\left(\frac{\alpha}{r-\gamma_{Y}+\gamma_{N}}\right)\left(\frac{m-1}{m}\right)\left(\frac{Y_{t}}{N_{t}}\right) .
$$

From combining the previous equation with (14), (16) and (29), we have:

$$
w_{t}^{N}=\left(\frac{\gamma_{N}}{s_{N}}\right)\left(\frac{\alpha}{r-\gamma_{Y}+\gamma_{N}}\right)\left(\frac{m-1}{m}\right)\left(\frac{Y_{t}}{H_{t}}\right) .
$$

Next, we use (3) to get:

$$
w_{t}^{Y}=\frac{(1-\alpha)}{s_{Y}}\left(\frac{Y_{t}}{H_{t}}\right) \text {. }
$$

Perfect mobility of human capital across sectors implies $w_{t}^{I}=w_{t}^{Y}$. Hence, from (32) and (34) we obtain:

$$
S_{Y}=\frac{m(1-\alpha)}{\alpha(1-\beta)} S_{I} .
$$

Perfect mobility of human capital also implies $w_{t}^{I}=w_{t}^{N}$. So, from (32) and (33) we also get:

$$
s_{N}=\left(\frac{\gamma_{N}}{r-\gamma_{Y}+\gamma_{N}}\right)\left(\frac{m-1}{1-\beta}\right) s_{I} .
$$

It is immediate to notice that, ceteris paribus, $s_{N}=0$ when $m=1$. Accordingly, $\gamma_{N}=0$ as well, from (29). When $m>1$, instead, $s_{N}>0$ and $\gamma_{N}>0$, too. From combining (1) and (11), we have:

$$
Y_{t}=A B^{\alpha} s_{Y}^{1-\alpha} S_{I}^{\alpha(1-\beta)} N_{t}^{\alpha(m-1)} H_{t}^{1-\alpha \beta} K_{t}^{\alpha \beta} .
$$

Using the last expression, and the fact that along a symmetric BGP the sectorial allocation of human capital remains constant, we are able to obtain the following relationship among the different growth rates of the variables:

$$
\gamma_{Y}=\alpha(m-1) \gamma_{N}+(1-\alpha \beta) \gamma_{H}+\alpha \beta \gamma_{K} .
$$

Through (27), the last equation can be recast as a relation between $\gamma_{Y}, \gamma_{N}$, and $\gamma_{H}$ :

$$
\gamma_{Y}=\Delta \gamma_{N}+\gamma_{H}, \quad \Delta \equiv\left(\frac{\alpha}{14 \overline{2} \frac{\alpha \beta}{>0}}\right)(m-1)
$$


Eq. (37) shows the effect on the aggregate GDP growth rate of the two possible growth engines of this economy: human capital accumulation and R\&D. Note that $\Delta$ measures the strength of the growth effect of R\&D. This effect crucially depends on $m$ : when there is perfect competition in the intermediate product market ( $m=1$ ), then $\Delta=0$ and the only engine of economic growth is human capital investment. In contrast, when the intermediate product market is imperfectly competitive $(m>1)$, then $\Delta>0$ and increases in $\alpha$ and/or $\beta$ make economic growth more responsive, through a rise of $\Delta$, to changes in R\&D investment. This result is easy to explain in the light of the fact that $\alpha$ measures the share of GDP going to intermediate inputs, and $\beta$ controls the physical/human capital-input intensity in the intermediate inputs sector. Concerning more specifically the economic impact of the latter parameter, it is worth noting that along a symmetric BGP equilibrium $\beta$ plays a fundamental role in affecting variables like the wage going to human capital employed in the intermediate sector (Eq. 32) and, hence, the sectorial allocation of human capital (Eqs. 35 and 36), and the level and growth rate of income (Eq. 37). It is apparent that in most of these equations (especially 32, 35 and 36) the assumption $0<\beta<1$, which represents our main departure from Romer's (1990) treatment of the intermediate sector technology, is a useful generalization capable of avoiding too much specific results.

As a final comment, after denoting by $y \equiv Y / L$ the level of per capita GDP and by $\gamma_{y}$ its growth rate, one may immediately see that along a symmetric BGP equilibrium Assumption A can be re-cast as:

$$
(\theta-1) \gamma_{y}+(\rho-n)+\gamma_{N}>0
$$

For any $\rho>n$ (which holds in our model), the above inequality is always satisfied when (sufficient condition)

$$
\gamma_{y} \geq 0, \quad \gamma_{N} \geq 0, \quad \text { and } \quad \theta \geq 1 .
$$

While the first two restrictions ( $\gamma_{y} \geq 0$ and $\gamma_{N} \geq 0$ ) are easy to understand as this paper is interested in unveiling and characterizing, among the two possible ones, the ultimate source(s) of long-run economic growth, the last one $(\theta \geq 1)$ deserves instead some caution as it has to do with the magnitude of the intertemporal elasticity of substitution in consumption, a parameter that generally plays a crucial role in growth theory. However, since Hall (1988a) empirical investigations bring convincing evidence (see, for example, Growiec, 2006, p. 17-18) that $\theta>1$. This $(\theta>1)$ is exactly the assumption that Strulik (2005, Eq. 22, p. 135) uses to establish his results in a theoretical work related to the present one.

Before analyzing the different types of long-run equilibria that may emerge from the model outlined above, we now introduce some further definitions.

Definition 3: Let $\gamma_{y}$ be the growth rate of per capita GDP. Then, 
(i) Economic growth is semi-endogenous when $\gamma_{y}$ is determined neither by the TFP of the R\&D technology, nor by the TFP of the education technology;

(ii) Economic growth is fully endogenous when $\gamma_{y}$ is determined either by the TFP of the R\&D technology, or by the TFP of the education technology, or by both TFPs;

(iii) A steady state equilibrium is an equilibrium in which $\gamma_{y}$ equals zero. We claim that the steady state is asymptotic if $\gamma_{y}$ equals zero only when either $N_{t}$ or $H_{t}$ diverge to infinity;

(iv) A BGP equilibrium is an equilibrium in which $\gamma_{y}$ is constant and positive. We claim that the BGP is asymptotic if $\gamma_{y}$ is constant only when either $N_{t}$ or $H_{t}$ diverge to infinity;

(v) Growth is unbounded when $\gamma_{y}$ diverges to infinity in the very long-run.

Depending on the value of the parameters, the long-run equilibria of this model can be any of the previous possibilities. However, in the remainder of the paper we only focus on BGP equilibria that are attained non-asymptotically. Moreover, we do not consider long-run equilibria in which economic growth is unbounded (as this case is not supported by available empirical evidence), and also neglect cases in which sustained growth is not feasible. The following proposition lists the possible types of BGP equilibrium that may arise from our model, depending on the values of $\varepsilon, \phi, \mu$, and $n .{ }^{10}$

Proposition 1. Assume $\dot{L}_{t} / L_{t} \equiv n \geq 0$ and $m>1$. The long-run equilibrium:

a) Is a BGP equilibrium with fully endogenous per capita income growth driven by human capital investment if $\varepsilon<1, \phi<1$, and $\mu=1$.

b) Is a BGP equilibrium with fully endogenous per capita income growth driven by $R \& D$ investment if $\varepsilon=1, \phi=1$, and $\mu<1$.

c) Is a BGP equilibrium with fully endogenous per capita income growth driven by both engines (human capital and $R \& D$ investments) if $\varepsilon=1, \phi=1$, and $\mu=1$.

d) Is a BGP equilibrium with semi-endogenous per capita income growth if $\varepsilon<1, \phi<1, \mu<1$, and $n>0$.

10 The model also yields long-run equilibria different from the BGP. In particular, the long-run equilibrium is an asymptotic BGP equilibrium with fully endogenous per capita income growth driven by either human capital investment if $\varepsilon<1, \phi=1$ and $\mu=1$, or by R\&D investment if $\varepsilon=1, \phi<1, \mu<1$ and $n=0$. The long-run equilibrium yields either unbounded and semi-endogenous per capita income growth driven by human capital investment if $\varepsilon=1, \phi<1, \mu<1$ and $n>0$, or unbounded and fully endogenous per capita income growth driven by human capital investment if $\varepsilon=1, \phi<1$ and $\mu=1$. Finally, the long-run equilibrium is an asymptotic steady state equilibrium either with aggregate accumulation of human capital if $\varepsilon<1, \phi=1$ and $\mu<1$, or without aggregate accumulation of human capital if $\varepsilon<1, \phi<1, \mu<1$ and $n=0$. 
Proof: Follows from Eqs. (29) and (37) and the fact that, under (19) and the definition of $n \equiv \dot{L}_{t} / L_{t}$, the growth rate $\left(\gamma_{H}\right)$ of aggregate human capital $\left(H_{t}=L_{t} h_{t}\right)$ is: $\gamma_{H}=\sigma\left(1-u_{t}\right) h_{t}^{\mu-1}$.

From the comparison of the four cases, it is clear that growth is driven by human capital investment only when there are constant returns to scale in the education technology, which occurs when $\mu=1$. Similarly, growth is driven by $R \& D$ investment if there are constant returns to scale in $R \& D$, which occurs when $\varepsilon=1, \phi=1$. Finally, sustained growth is semi-exogenous and driven by population growth when there are decreasing returns to scale in both the education and the R\&D technologies.

\section{Long-run equilibria: The relationship between population growth and economic growth}

In this section we study separately the four cases listed in Proposition 1. In each of them, we describe the long-run equilibrium and perform comparative statics with respect to population growth. This is done in order to find how the long-run relationship between population and economic growth rates might eventually change depending on the underlying engine (human capital investment, R\&D activity, or both) and nature (fully- or semi-endogenous) of economic growth.

\subsection{Case (a): Human capital investment as the sole engine of fully endogenous economic growth}

Proposition 2. Assume $\varepsilon<1, \phi<1$, and $\mu=1$. Then, the growth rates of per capita GDP, aggregate human capital and number of varieties are, respectively

$$
\begin{gathered}
\gamma_{y}=\frac{(1+\Omega)(\sigma-\rho)+n}{\theta(1+\Omega)-1} \\
\gamma_{H}=\frac{\Omega(\sigma-\rho+\theta n)}{\theta(1+\Omega)-1}
\end{gathered}
$$

and

$$
\gamma_{N}=\left\{\begin{array}{lll}
\left(\frac{1-\phi}{1-\varepsilon}\right) \gamma_{H} & \text { if } & m>1 \\
0 & \text { if } & m=1
\end{array}\right.
$$

where

$$
\Omega \equiv\left(\frac{1}{\Delta}\right)\left(\frac{1-\varepsilon}{1-\phi}\right) .
$$


Proof: Online-Appendix B.

In this case, the growth rate of per capita income is fully endogenous and driven solely by human capital investment. This is immediately apparent not only from the fact that in the long-run the growth rate of the number of varieties $\left(\gamma_{N}\right)$ is itself, if $m>1$, eventually induced by the growth of human capital $\left(\gamma_{H}\right)$, but also from the observation that for any $m \geq 1$ the per capita GDP growth rate depends on the TFP of the human capital investment sector $(\sigma)$ and is independent of the TFP of the other sectors of the economy. For any $m \geq 1$ and $n \geq 0$, the following assumption provides sufficient conditions for economic growth $\left(\gamma_{y}\right)$ to be positive.

Assumption B: $\quad \sigma>\rho \quad$ and $\quad \theta>\frac{1}{1+\Omega} \in[0,1)$

When $m=1$, this case reproduces Lucas (1988) as the per capita income growth rate is $\gamma_{y}=(\sigma-\rho) / \theta$.

Proposition 3. If $\varepsilon<1, \phi<1, \mu=1$, and Assumption $B$ is satisfied, then the growth rate of per capita income:

a) Increases with the TFP of the education sector and is independent of the TFP of the R\&D sector;

b) Increases with the population growth rate if $m>1$;

c) Is independent of the population growth rate if $m=1$.

Proof: Follows immediately from the expression of the growth rate of per capita income in Proposition 2.

In this framework, new designs are created only in the presence of human capital accumulation. Therefore, as long as there are both human capital investment and the indispensable reward from conducting innovation activity $(m>1)$, the R\&D sector is operative in the long-run. In turn, because human capital is positively correlated with population, a rise in the population growth rate by increasing the growth rate of human capital (the sole engine of economic growth) leads, ceteris paribus, to a higher growth rate of per capita GDP. Interestingly, this economic growth effect of population change does not emerge when there is perfect competition in the intermediate sector $(m=1)$, as in this case there are insufficient incentives to produce new ideas (the R\&D sector is not operative in the long-run). In other words, in this model population growth can stimulate economic growth only through its positive effect on the expansion in the number of available varieties ("...More people means more Isaac Newtons and therefore more ideas...”, Jones 2003, p. 505). 


\subsection{Case (b): R\&D activity as the sole engine of fully endogenous economic growth}

Proposition 4. Assume $\varepsilon=1, \phi=1, \mu<1$, and $m>1$. Then, the growth rates of per capita GDP, aggregate human capital and number of varieties are, respectively

$$
\begin{gathered}
\gamma_{y}=\frac{r-\rho}{\theta} \\
\gamma_{H}=n
\end{gathered}
$$

and

$$
\gamma_{N}=\frac{r-\rho}{\theta \Delta}
$$

where $r=P(\rho \chi, n, \theta, \rho, m, \alpha, \beta)$ is obtained in implicit form in Online-Appendix $C$.

Proof: Online-Appendix C.

We focus on $m>1$ because with $m=1$ the growth rate of per capita income $\left(\gamma_{y}\right)$ would be equal to zero (this is a direct consequence of the fact that, ceteris paribus, the instantaneous profit going to any generic intermediate firm and, therefore, the price of the corresponding idea are both equal to zero when $m=1$, see Eqs. 12 and 17).

When $m>1$, the growth rate of per capita income is fully endogenous and driven by R\&D investment. In order to obtain an explicit solution, we assume that the instantaneous utility function is logarithmic $(\theta=1)$. In this case, the real interest rate simplifies to

$$
r=\rho(\rho \chi, n)=\rho+\left[\frac{1}{\rho \chi}-\frac{\alpha(1-\beta)+m(1-\alpha)}{\alpha(m-1)}\right]\left[\frac{\alpha \Delta(\rho-n)(m-1)}{(m-\alpha \beta)}\right],
$$

and the growth rate of per capita GDP is

$$
\gamma_{y}=r-\rho=\left[\frac{1}{\rho \chi}-\frac{\alpha(1-\beta)+m(1-\alpha)}{\alpha(m-1)}\right]\left[\frac{\alpha \Delta(\rho-n)(m-1)}{(m-\alpha \beta)}\right] .
$$

Assumption $C$ provides a minimum value of the R\&D TFP above which the growth rate of per capita GDP is positive when $\theta=1$ and $m>1$.

Assumption C: $\frac{1}{\chi}>\left[\frac{\alpha(1-\beta)+m(1-\alpha)}{\alpha(m-1)}\right] \rho>0$.

Proposition 5. If $\theta=1, m>1, \varepsilon=1, \phi=1, \mu<1$, and Assumption $C$ is satisfied, then the growth rate of per capita income:

a) Increases with the TFP of the R\&D sector and is independent of the TFP of the education sector;

b) Decreases with the population growth rate. 
Proof: Results follow immediately from the growth rate of per capita income with $\theta=1$ and $m>1$.

In this case, the growth rate of per-capita income is fully endogenous and driven solely by $R \& D$ investment. However, the education sector is still operative although its task is just to provide human capital to the newborns $\left(\gamma_{H}=n\right)$. This explains why an increase in the TFP of the education sector has no impact on economic growth, while an increase in the TFP of the R\&D sector has a positive effect on per capita income growth. Regarding the growth effects of population change, note that a faster population growth, by raising the aggregate investment in human capital, re-allocates resources away from the true growth engine (the $R \& D$ sector). As a consequence, the growth of new designs and, hence, the growth of per capita GDP are lowered by this re-allocation of resources induced by a higher population growth rate. This result holds when $\theta=1$. In order to see whether the economic growth impact of population change is somehow affected by the magnitude of $\theta$, we simulate the model of this section under three different values of $\theta\left(\theta=1, \theta=2\right.$, and $\theta=0.5$, respectively). ${ }^{11}$ The values of the parameters and targets of the simulation are shown in Table 1, while the numerical results are illustrated in Figure 1 (tables and figures are placed at the end of the paper). We observe that in the three scenarios a larger population growth rate leads to a larger growth rate of aggregate human capital but also to a lower growth rate of the number of new designs. In the three scenarios, the growth rate of per-capita GDP decreases with population growth. Thus, the analytical results obtained and discussed under $\theta=1$ seem to be robust to deviations of $\theta$ away from one. This, in turn, supports the conclusion that the model outlined in this section provides a new mechanism able to explain why in the long-run the association between population and economic growth rates could be negative even in R\&D-based growth models. The proposed mechanism relies on the presence of a re-allocation of resources from growth-generating towards growth non-generating economic activities due to population growth.

\subsection{Case (c): Human capital investment and $R \& D$ activity as twin engines of fully endogenous economic growth}

Proposition 6. Assume $\varepsilon=1, \phi=1, \mu=1$, and $m>1$. The growth rates of per capita GDP, aggregate human capital and number of varieties are, respectively

$$
\begin{gathered}
\gamma_{y}=\frac{(\sigma-\rho)+(n-\rho) \lambda}{(\theta-1) \lambda+\theta} \\
\gamma_{H}=\frac{\sigma[1-(1-\theta) \lambda]-\rho+\theta n}{(\theta-1) \lambda+\theta}
\end{gathered}
$$

11 It is possible to show that Assumption A is satisfied in the three cases. 
and

$$
\gamma_{N}=\left(\frac{\lambda}{\Delta}\right)\left[\frac{\sigma-\rho+\theta(n-\sigma)}{(\theta-1) \lambda+\theta}\right]
$$

where

$$
\lambda \equiv\left(\frac{\Delta \alpha}{m-\alpha \beta}\right)\left[\frac{(1-\alpha)(m-1)}{\alpha}+\left(\frac{1-\alpha \beta}{\alpha}\right)-\frac{(m-1)}{\sigma \chi}\right]
$$

Proof: Online-Appendix C.

If $m=1$ then $\lambda=\Delta=0$ and the growth rate of per capita GDP coincides with the growth rate of human capital per capita, i.e. human capital accumulation is the only growth engine. When this occurs, the growth rate of the economy is $\gamma_{y}=(\sigma-\rho) / \theta$, hence economic growth is independent of population growth. In contrast, if $m>1$ the growth rate of per capita GDP is driven by both engines (human capital investment and R\&D activity). In the remainder of this section we assume $m>1$, as we are interested in analyzing the long-run correlation between population and economic growth rates under the simultaneous presence of two engines of growth. We now introduce the following assumptions.
Assumption D. $\quad[(\theta-1) \lambda+\theta]>0$
and

$$
(\sigma-\rho)>(\rho-n) \lambda
$$

Assumption E. $\quad[\sigma-\rho+\theta(n-\sigma)]<0 \quad$ and $\quad \lambda<0$.

While Assumption D guarantees a positive growth rate of per capita GDP, Assumption E ensures that the fraction of human capital devoted to working activities $(u)$ and the innovation rate $\left(\gamma_{N}\right)$ are simultaneously positive (see Online-Appendix D).

Proposition 7. If $\varepsilon=1, \phi=1, \mu=1$, and $m>1$, then the growth rate of per capita income:

a) Depends in an ambiguous manner on the total factor productivity of the education sector;

b) Increases with the total factor productivity of the $R \& D$ sector;

c) Decreases with the population growth rate.

Proof: Results (a) and (b) are demonstrated in Online-Appendix D. Result (c) follows immediately from the growth rate of per capita GDP (Proposition 6) when Assumptions D and E are satisfied. 
According to Proposition 7 (result $a$ ), in a model where economic growth is fully endogenous and jointly driven by human capital investment and $R \& D$ activity, increasing the TFP of the education sector may also yield a negative impact on economic growth. This result is clearly different from what one may find in models where economic growth is driven solely by skill acquisition (see case (a) in this paper, for an example). In order to provide some intuition, we simulate the model of this section. The values of the parameters and targets of the simulation are shown in Table 1, while the numerical results are illustrated in Figure 2. As shown in Figure 2, when $\sigma$ increases we see that a re-allocation effect towards the education sector takes place in the economy, i.e. the growth rate of $N$ decreases while the growth rate of $H$ increases. Hence, the GDP growth rate of the economy may either fall or rise. We also notice that the magnitude of this effect changes with the size of $\sigma$. An increase in $\sigma$ has as a whole a negative impact on the rate of economic growth when $\sigma$ is small enough: in this case, following a marginal increase in the TFP of the education sector, the re-allocation effect would be strong (the reduction in the growth rate of $N$ would be larger than the concomitant increase in the growth rate of $H$ due to a higher TFP in this sector). The contrary occurs when $\sigma$ is large enough (in this case the re-allocation effect would be weak so that the decline in the growth rate of $N$ would be smaller than the parallel rise in the growth rate of $H$ due to a higher education-sector TFP).

Results (a) and (b) in Proposition 7 show that the two engines of growth are concurrently active in this framework. Result (c) can, thus, be explained by taking into account that the two growth engines are in place. An increase in population growth, while raising the growth rate of $H$, also reduces the growth rate of $N$, the share of human capital used in R\&D and the whole employment share, $u$ :

$$
u=s_{Y}+s_{I}+s_{N}=\frac{\sigma(\theta-1)+\rho-\theta n}{\sigma[(\theta-1) \lambda+\theta]} .
$$

All this ultimately leads to a smaller growth rate of per capita GDP in the long-run. This result, together with a similar result obtained in the model of the previous section, allows us to conclude that, contrary to traditional R\&D-based growth models, in this economy whenever R\&D activity is an engine of economic growth (either alone, or in conjunction with human capital investment) in the long-term population growth may be negatively correlated with per capita GDP growth through a re-allocation effect.

\subsection{Case (d): Human capital investment as the sole engine of semi-endogenous economic growth}

Proposition 8. Assume $\varepsilon<1, \phi<1, \mu<1$, and $n>0$. Then, the growth rates of per capita GDP, aggregate human capital and number of varieties are, respectively 


$$
\begin{gathered}
\gamma_{y}=\Delta\left(\frac{1-\phi}{1-\varepsilon}\right) n \\
\gamma_{H}=n,
\end{gathered}
$$

and

$$
\gamma_{N}=\left\{\begin{array}{lll}
\left(\frac{1-\phi}{1-\varepsilon}\right) n & \text { if } & m>1 \\
0 & \text { if } \quad m=1
\end{array}\right.
$$

\section{Proof: Online-Appendix E.}

In this case, we have a BGP equilibrium with semi-endogenous per capita income growth driven solely by exogenous population growth (human capital investment). Note that economic growth is independent of the total factor productivities of the different sectors of the economy, and crucially depends on the markup. If there were perfect competition in the intermediate sector $(m=1)$, then per capita GDP would not grow even in the presence of a positive population growth rate. Hence, in this case $(m=1)$, population growth would not have any role in economic growth. Once again this confirms that in the present context population growth can stimulate per capita income growth only through its positive effect on the expansion in the number of available varieties $(m>1)$.

Proposition 9. If $\varepsilon<1, \phi<1, \mu<1$, and $n>0$, the growth rate of per capita income:

a) Does depend neither on the total factor productivity of the education sector, nor on that of the $R \& D$ sector;

b) Increases with the population growth rate iff there is imperfect competition in the intermediate product market $(m>1)$;

c) Would be equal to zero in the presence of perfect competition in the intermediate product market $(m=1)$.

Proof. Follows immediately from the growth rate of per capita GDP written in Proposition 8.

In this framework the growth rate of per-capita income is semi-endogenous in the sense that it is driven solely by population growth, an exogenous variable: a faster population growth, by raising the aggregate investment in human capital, contributes positively to raise the number of available varieties of intermediate inputs, and therefore economic growth. This explains why, when the market for the intermediate inputs is imperfectly competitive (so that the economic incentives to perform R\&D activity are large), an increase in the population growth rate boosts the growth rate of per capita income. 
This result implicitly suggests the existence of a sort of complementarity between market power and population growth. An increase in the markup, by encouraging profit-oriented agents to perform more R\&D, amplifies the positive effect that an expansion of population may have on economic growth through the availability of a major number of scientists and engineers (human capital). Similarly, a larger population, by raising the availability of human capital in the economy and, hence, the number of people engaged in $R \& D$, strengthens the positive effect that an increase in the markup may have on economic growth through innovation. ${ }^{12}$

\section{Discussion and Concluding Remarks}

Simple comparison across the four cases analyzed in the previous section reveals that the economy's long-run growth rate of per capita income can be affected by the TFP of the R\&D sector only if there are aggregate constant returns to scale in $\mathrm{R} \& \mathrm{D}$, which occurs in cases (b) and (c). Similarly, the long-run growth rate of per capita income can be affected by the TFP of the education sector only if there are aggregate constant returns to scale in education, which occurs in cases (a) and (c). In case (d) economic growth is semi-endogenous and, therefore, independent of the TFP of the education and R\&D sectors. Thus, only when $\varepsilon=\phi=\mu=1$ (case $c$ ) both TFPs can simultaneously affect the growth rate of per capita income, meaning that the two growth engines (R\&D activity and human capital investment) are active at the same time.

The present paper has also shown that the long-run economic effects of population change depend on the specific engine(s) driving economic growth. When human capital is the sole engine of growth or growth is semi-endogenous, population growth has in general (i.e., when $m>1$ ) a positive effect on economic growth. In both cases, the positive growth-effect of population arises because population change causes an increase in the aggregate stock of human capital, which leads to a concomitant rise in the growth of varieties and, hence, in the growth rate of per capita GDP.

In contrast, population growth has in general (i.e., when $m>1$ ) a negative effect on economic growth when R\&D activity is the (sole or twin) engine of fully-endogenous economic growth. This is explained by the fact that a larger population growth by raising the aggregate investment in human capital reallocates resources away from the R\&D sector, which ultimately determines a fall in the per capita income growth rate (in other words, a change in population growth causes a re-distribution of the available human capital across sectors).

12 Formally, $\frac{\partial}{\partial m}\left(\frac{\partial \gamma_{y}}{\partial n}\right)>0$. 
When $m=1$, the economy lacks the traditional economic incentives (profits) that lead people to make an effort in discovering new ideas, and the R\&D sector is not operative. In this context, a change in the growth rate of population has no effect on per capita income growth because the individual motivation to invest in education is eventually related to (technological and/or preference) parameters that are independent of the population growth rate.

Taken together, our results suggest that following a given change in the population growth rate we may observe different (both in sign and in magnitude) economic growth effects depending on the peculiar engine and the specific nature of the process of economic growth.

Though the present paper has limited itself to emphasize another possible channel (complementary with others already existing) through which we can explain the presence of some variability in the ultimate long-run impact of population change on economic growth, we believe that our approach may also be useful for further theoretical and empirical work along the lines recently suggested by Ertur and Koch (2011). By recognizing that in real world countries can no longer be considered as isolated entities or independent observations and that global technological interdependences/spillovers between them need to be explicitly taken into account, these two authors have proposed a new integrated theoretical and methodological multi-country framework in which worldwide R\&D interactions play a crucial role. While spatial econometric methodology is shown to represent the indispensable tool for empirically dealing with this issue, Ertur and Koch (2011) also demonstrate that the multi-country pure Solow growth model is rejected in favor of the multi-country Schumpeterian growth model once both models are unified in the same framework characterized by the existence of international technological externalities. The theoretical extension of our model to a multi-country framework with $R \& D$ spillovers and the formal empirical investigation of its main predictions through the use of the tools recently developed by spatial econometrics are left as a suggestion for future research.

\section{REFERENCES}

Barro, R.J., Lee, J.-W. (2010). A new data set of educational attainment in the world, 1950-2010. NBER Working Paper No. 15902, April.

Basu, S. (1996). Procyclical productivity: Increasing returns or cyclical utilization? Quarterly Journal of Economics, 111(3), 719-751.

Bils, M., Klenow, P.J. (2000). Does schooling cause growth? American Economic Review, 90(5), 11601183.

Boikos, S., Bucci, A., Stengos, T. (2013). Non-monotonicity of fertility in human capital accumulation and economic growth. Journal of Macroeconomics, 38, 44-59.

Boserup, E. (1981). Population and Technical Change: A Study of Long-Term Trends. Chicago: University of Chicago Press. 
Boucekkine, R., de la Croix, D., Licandro, O. (2002). Vintage human capital, demographic trends, and endogenous growth. Journal of Economic Theory, 104(2), 340-375.

Boucekkine, R., Martínez, B., Ruiz-Tamarit, J.R. (2013). Growth vs. level effect of population change on economic development: An inspection into human capital-related mechanisms. Journal of Mathematical Economics, 49(4), 312-334.

Bucci, A. (2008). Population Growth in a Model of Economic Growth with Human Capital Accumulation and Horizontal R\&D. Journal of Macroeconomics, 30(3), 1124-1147.

Bucci, A. (2013). Returns to specialization, competition, population, and growth. Journal of Economic Dynamics\&Control, 37(10), 2023-2040.

Chang, J.-j., Hung, H.-w., Huang, C.-c. (2011). Monopoly power, increasing returns to variety, and local indeterminacy. Review of Economic Dynamics, 14(2), 384-388.

Coale, A.J., Hoover, E. (1958). Population Growth and Economic Development in Low-Income Countries. Princeton: Princeton University Press.

Ehrlich, P.R. (1968). The Population Bomb. New York: Ballentine.

Ertur, C., Koch, W. (2011). A contribution to the theory and empirics of Schumpeterian growth with worldwide interactions. Journal of Economic Growth, 16(3), 215-255.

Galor, O. (2005). From Stagnation to Growth: Unified Growth Theory. In Aghion, P. and S.N. Durlauf (Eds.), Handbook of Economic Growth. Amsterdam: Elsevier-North Holland, Chap. 4, pp. 171-293.

Galor, O., Moav, O. (2002). Natural selection and the origin of economic growth. Quarterly Journal of Economics, 117(4), 1133-1191.

Galor, O., Weil, D.N. (1999). From Malthusian stagnation to modern growth. American Economic Review, 89(2), 150-154.

Galor, O., Weil, D.N. (2000). Population, technology, and growth: From Malthusian stagnation to the demographic transition and beyond. American Economic Review, 90(4), 806-828.

Gong, G., Greiner, A., Semmler, W. (2004). The Uzawa-Lucas model without scale effects: Theory and empirical evidence. Structural Change and Economic Dynamics, 15(4), 401-420.

Growiec, J. (2006). Fertility choice and semi-endogenous growth: Where Becker meets Jones. B.E. Journal of Macroeconomics: Topics in Macroeconomics, 6(2), 1-23.

Ha, J., Howitt, P. (2007). Accounting for trends in productivity and R\&D: A Schumpeterian critique of semi-endogenous growth theory. Journal of Money, Credit and Banking, 39(4), 733-774.

Hall, R.E. (1988). The relationship between price and marginal cost in U.S. industry. Journal of Political Economy, 96(5), 921-947.

Hall, R.E. (1988a). Intertemporal substitution in consumption. Journal of Political Economy, 96(2), 339357.

Hall, R.E. (1990). Invariance properties of Solow's productivity residual. In: P. Diamond (Ed.), Growth, Productivity, Unemployment. Cambridge, MA: MIT Press, pp. 71-112.

Herzer, D., Strulik, H., Vollmer, S. (2012). The long-run determinants of fertility: One century of demographic change, 1900-1999. Journal of Economic Growth, 17(4), 357-385.

Jones, C.I. (1995). R\&D-Based Models of Economic Growth. Journal of Political Economy, 103(4), 759784.

Jones, C.I. (2001). Was an industrial revolution inevitable? Economic growth over the very long run. Advances in Macroeconomics, 1(2), 1-43.

Jones, C.I. (2002). Sources of U.S. economic growth in a world of ideas. American Economic Review, 92(1), 220-239.

Jones, C.I. (2003). Population and Ideas: A Theory of Endogenous Growth. In Aghion, P., Frydman, R., Stiglitz, J. and M. Woodford (Eds.), Knowledge, Information, and Expectations in Modern Macroeconomics: In Honor of Edmund S. Phelps. Princeton: Princeton University Press, pp. 498-521.

Jones, C.I. (2005). Growth and Ideas. In Aghion, P. and S.N. Durlauf (Eds.), Handbook of Economic Growth. Amsterdam: Elsevier-North Holland, Chap. 16, pp. 1063-1111.

Kelley, A.C., Schmidt, R.M. (1995). Aggregate population and economic growth correlations: The role of the components of demographic change. Demography, 32(4), 543-555. 
Kogel, T., Prskawetz, A. (2001). Agricultural productivity growth and escape from the Malthusian trap. Journal of Economic Growth, 6(4), 337-357.

Kremer, M. (1993). Population growth and technological change: One million B.C. to 1990. Quarterly Journal of Economics, 108(3), 681-716.

Kuznets, S. (1967). Population and Economic Growth. Proceedings of the American Philosophical Society, 111(3), 170-193.

Li, H., Zhang, J. (2007). Do high birth rates hamper economic growth? Review of Economics and Statistics, 89(1), 110-117.

Lucas, R.E. (1988). On the mechanics of economic development. Journal of Monetary Economics 22(1), 3-42.

Malthus, T.R. (1798). An Essay on the Principle of Population. London: W. Pickering (1986 Edition).

Mierau, J.O., Turnovsky, S.J. (2014). Demography, growth, and inequality. Economic Theory, 55(1), 2968.

Mincer, J. (1974). Schooling, Experience, and Earnings. New York: Columbia University Press.

Morrison, C.J. (1990). Market power, economic profitability and productivity growth measurement: An integrated structural approach. NBER Working Paper No. 3355.

Mulligan, C.B., Sala-i-Martin, X. (1993). Transitional dynamics in two-sector models of endogenous growth. Quarterly Journal of Economics, 108(3), 739-773.

Norrbin, S.C. (1993). The relation between price and marginal cost in U.S. Industry: A contradiction. Journal of Political Economy, 101(6), 1149-1164.

Prettner, K. (2014). The non-monotonous impact of population growth on economic prosperity. Economics Letters, 124(1), 93-95.

Psacharopoulos, G., Patrinos, H.A. (2004). Returns to investment in education: A further update. Education Economics, 12(2), 111-134.

Roeger, W. (1995). Can imperfect competition explain the difference between primal and dual productivity measures? Estimates for U.S. manufacturing. Journal of Political Economy, 103(2), 316330.

Romer, P.M. (1986). Increasing returns and long-run growth. Journal of Political Economy, 94(5), 10021037.

Romer, P.M. (1990). Endogenous technological change. Journal of Political Economy, 98(5), S71-S102.

Saccone, D., Valli, V. (2011). Economic development and population growth: An inverted-U shaped curve? University of Turin: Department of Economics "S. Cognetti de Martiis" Working Paper Series, Working paper No. 05/2011.

Simon, J. (1981). The Ultimate Resource. Princeton: Princeton University Press.

Solow, R.M. (1956). A contribution to the theory of economic growth. Quarterly Journal of Economics, 70(1), 65-94.

Strulik, H. (2005). The Role of Human Capital and Population Growth in R\&D-based Models of Economic Growth. Review of International Economics, 13(1), 129-145.

Strulik, H., Prettner, K., Prskawetz, A., (2013). The past and future of knowledge-based growth. Journal of Economic Growth, 18(4), 411-437.

Trostel, P.A. (2004). Returns to scale in producing human capital from schooling. Oxford Economic Papers, 56(3), 461-484.

United Nations (2013). World Population Prospects: The 2012 Revision, Key Findings and Advance Tables. Department of Economic and Social Affairs, Population Division, Working Paper No. ESA/P/WP.227.

Williamson, J.G. (2003). Demographic change, economic growth, and inequality. In N. Birdsall, A.C. Kelley and S.W. Sinding (Eds.), Population Matters: Demographic Change, Economic Growth, and Poverty in the Developing World. New York: Oxford University Press, Paperback Edition, pp. 106136. 


\section{TABLES AND FIGURES}

Here, we simulate numerically the models corresponding to cases (b) and (c) in the main text. The values of the parameters and the targets of the simulations are shown in Table $1 .{ }^{13}$

\begin{tabular}{|c|c|c|c|}
\hline \multicolumn{2}{|c|}{ CASE (b) } & \multicolumn{2}{|c|}{ CASE (c) } \\
\hline PARAMETERS & TARGETS & PARAMETERS & TARGETS \\
\hline $\mathrm{n}=1 \%$ & Population Growth & $n=1 \%$ & Population Growth \\
\hline$\alpha=0.8$ & GDP Growth = 1.9\% & $\alpha=0.73$ & GDP Growth $=1.9 \%$ \\
\hline$\beta=0.44$ & LIS $=65 \%$ & $\beta=0.4795$ & LIS $=65 \%$ \\
\hline $\mathrm{m}=1.4$ & Market Power & $\mathrm{m}=1.4$ & Market Power \\
\hline$\chi=3.85$ & $r=5.7 \%$ & $\chi=3.2$ & $r=5.7 \%$ \\
\hline$\theta=\{2 ; 1 ; 0.5\}$ & $\mathrm{IES}=\{0.5 ; 1 ; 2\}$ & $\theta=2$ & IES $=0.5$ \\
\hline$\rho=\{0.019 ; 0.038 ; 0.045\}$ & $\mathrm{C} / \mathrm{Y}=87 \%$ & $\rho=0.019$ & $\mathrm{C} / \mathrm{Y}=87 \%$ \\
\hline & & $\sigma=0.0337$ & $\mathrm{u}=83 \%$ \\
\hline
\end{tabular}

TABLE 1: The values of the parameters and targets of the numerical simulations corresponding to the models of Case (b) and Case (c) in the main text. ${ }^{14}$

13 Empirical estimates of the gross markup (the ratio of price to marginal cost) range from 1.05 to 1.4 according to Norrbin (1993) and Basu (1996). We choose $m=1.4$ because, although this value represents the upper bound of the above range, according to Chang et al. (2011, p. 387): “...Many empirical studies show that a markup ratio of 1.4 is plausible in practice. See, for example, Hall $(1988,1990)$, Morrison (1990), and Roeger (1995)...”. A population growth rate of $1 \%$ is used by Jones (2002, p. 232, Table 4 and Figure 5) and Boucekkine et al. (2013, p. 321). Although the magnitude of the IES has been estimated (since the path-breaking paper by Hall, 1988a) in a wide variety of works and with rather mixed results, empirical investigations bring convincing evidence that the IES is lower than one (Growiec, 2006, pp.17-18). Following Mulligan and Sala-i-Martin (1993, p. 761), we set the benchmark value of the IES to 0.5. GDP growth, the ratio of consumption expenditure to GDP, and the labor income share (LIS) are consistent with the US average values since the seventies. From the Barro and Lee (2010) Database on Educational Attainments (April 2010 release) it is possible to see that in 2010, for the total population aged 15-79 (so, 64 years) in 24 advanced countries (Australia, Austria, Belgium, Canada, Denmark, Finland, France, Germany, Greece, Iceland, Ireland, Italy, Japan, Luxembourg, Netherlands, New Zealand, Norway, Portugal, Spain, Sweden, Switzerland, Turkey, USA, and United Kingdom) the average amount of years of schooling was 11.03 (Barro and Lee, 2010, Table 3, p.32). This means that $u \cong 0.83$.

14 In Table 1, LIS and IES refer, respectively, to the Labor Income Share and to the Intertemporal Elasticity of Substitution in consumption. 

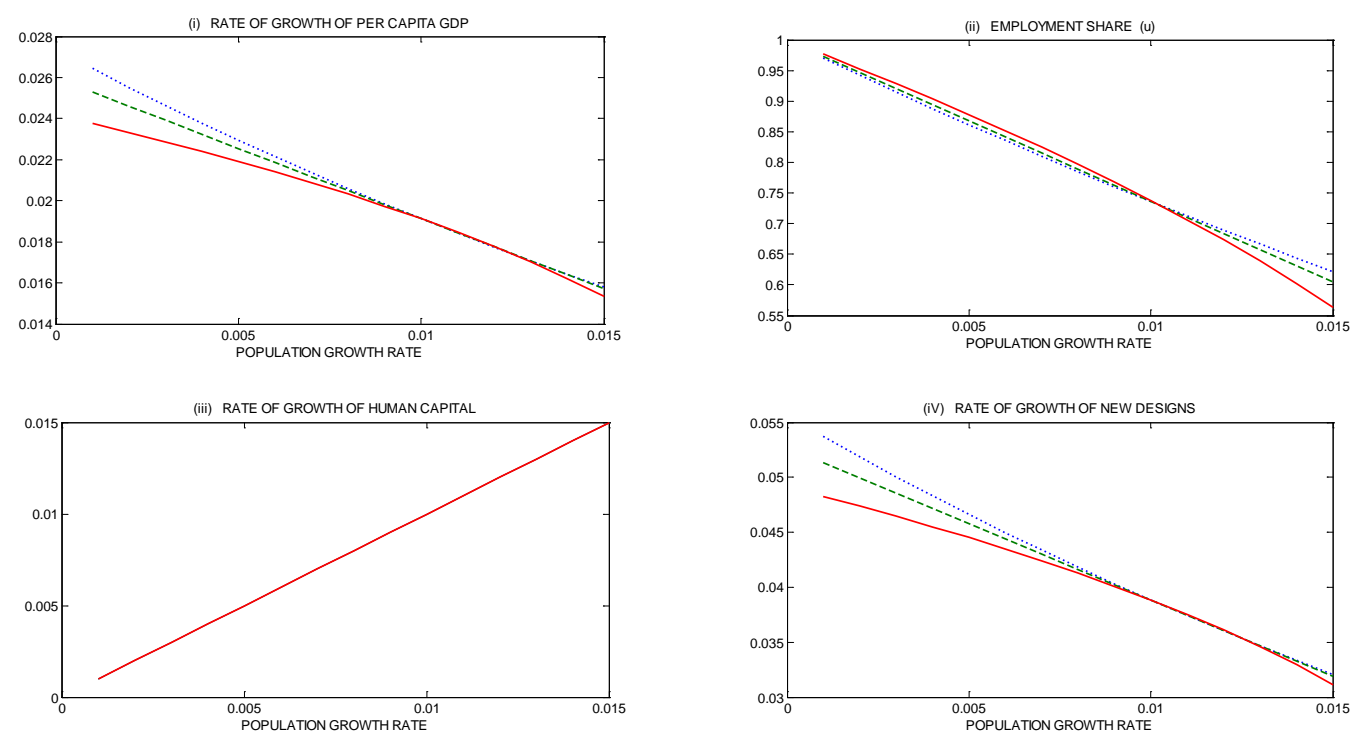

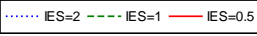

FIGURE 1: Numerical simulation, CASE (b)
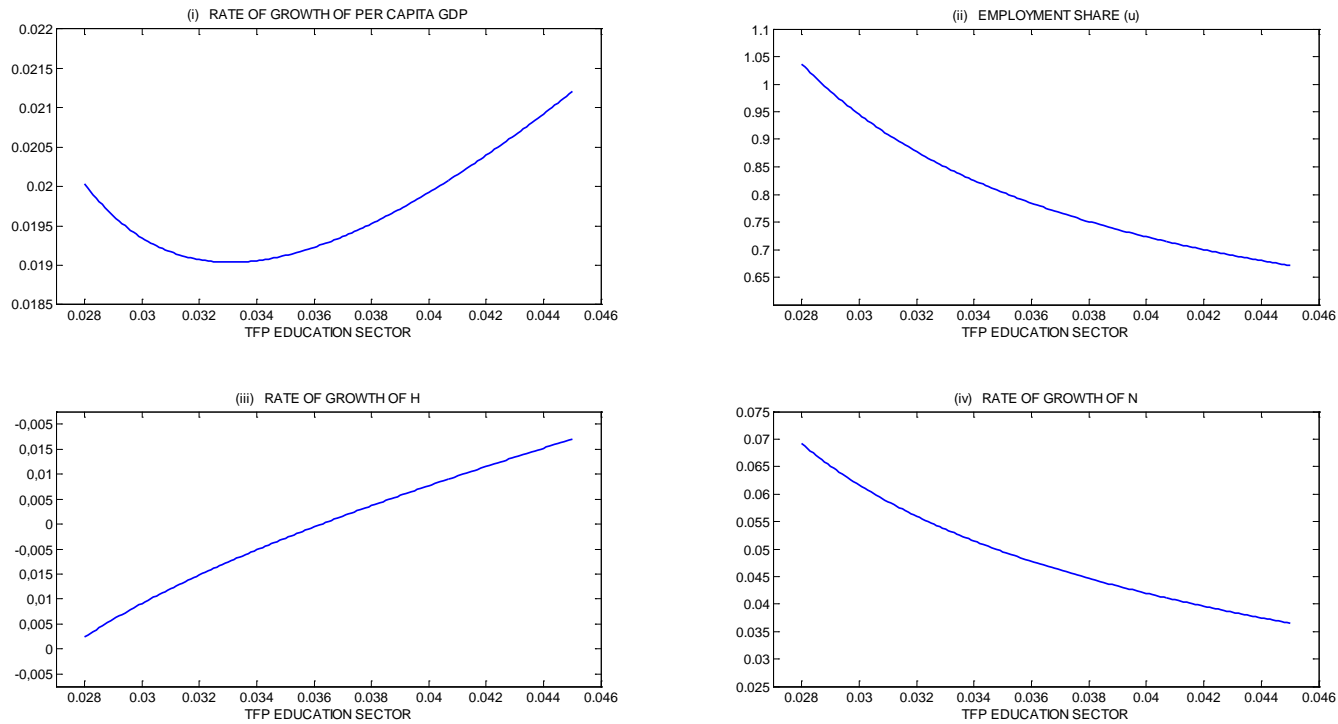

FIGURE 2: Numerical simulation, CASE (c) 